\title{
Marine Renewables Respecting the Environment
}

\author{
Olivia Langhamer* and Sverker Molander \\ Department of Technology Management and Economics, Chalmers University of Technology, Sweden
}

*Corresponding author: Olivia Langhamer, Department of Technology Management and Economics, Chalmers University of Technology, Gothenburg, Sweden

Submission: 㭗June 26, 2018; Published: 㘹 July 26, 2018

\begin{abstract}
Worldwide raising energy consumption demand gives a fast development of marine renewable energy (MRE). Here, we give a short overview on the risks and uncertainties that may affect the marine environment by these installations. Knowledge transfer from traditional offshore industries and the gain of new knowledge through environmental monitoring, applying old and new methods and standardised data collection will give further insights to understand changes induced by MRE on marine biodiversity and ecosystem functioning. Forecasting models for array effects will contribute to the indicating of MRE development respecting the environment.
\end{abstract}

\section{Introduction}

Political desire to mitigate the effects of climate change and meet the Sustainable Development Goals in a growing world economy with raising energy demand, fosters further development of and transition to all renewable energy. Hence, the development of marine renewable energy (MRE) sources will probably play a bigger role in contributing to the total energy supply. Human activities and pressures are extra strong in coastal and marine regions since these regions are of special interest due to the concentration of human population in coastal areas, and to their provision of ecosystem goods and services UNEP. 2006. Marine and coastal ecosystems and human wellbeing: a synthesis report based on the findings of Millennium ecosystem assessment. . However, this necessary change towards green energy should be carried out in association with respect of nature conservation and the sustainable use of the oceans and marine resources. The overuse and mismanagement of ecosystem services (ES)-e.g. through overexploitation, habitat loss and pollution have placed great pressure on marine systems and thereby threaten the future of marine ecosystems, and the services they provide [1-3].

Today, only offshore wind is commercial, but there is a worldwide proliferation of technologies and devices that harvest energy from waves, tides, ocean currents (and even from salinity and temperature differentials). Many MRE projects are planned as pre-commercial industrial projects, and numbers are expected to increase during the next decades [2]. This rather new industry raises a lot of questions around actual environmental impacts on, and potential risks to the marine ecosystem. Here, we define MRE more narrowly as technologies to harness waves and tidal currents, since the majority of environmental studies have focused on tidal and wave energy, with some emphasis on ocean current and river turbines [3]. Tidal energy and ocean current devices have progressed more rapidly than wave energy devices since technologies that resembled the design of wind turbines and ship propellers have been used (where EIAs already existed) so that the technology and its impacts are more familiar to regulators. Furthermore, the devices are often submerged and invisible from the surface, which might reduce attention from stakeholders. While an increased use of the marine space to satisfy energy demand appears highly probable, a variety of environmental impacts and risks have been identified for the MRE development and deployment [4]. However, little is known about how possible changes in biodiversity resulting from the deployment of MRE infrastructures might affect these highly dynamic and complex ecosystems including their functioning. There are many uncertainties involved in future installations and array development, and the desire for conservation and demand for space pose concerns in many countries. This knowledge gap can be explained by a lack of robust, standardised data collection across devices and methods that can inform adaptable prediction models and scenarios covering various tempo-spatial scales.

For many centuries, the sea has been explored and used for the ocean industries, and marine life has been observed and studied especially in connection with fisheries (e.g. population dynamics, effects of fishing gear, and on species composition and interactions), shipping (e.g. vessels, shipping routes, shipwrecks) and offshore energy (e.g. oil, gas, wind). The knowledge gained from these "traditional" industries can serve as a scientific foundation to inform our understanding of interactions between MRE devices and the marine ecosystem, and for understanding particular environmental stressors. One good example is the deployment of hard substrates either floating on the sea surface or 
being submerged on the seafloor, that can be colonised by different biofouling communities and work as fish aggregation devices or artificial reefs. Long-term environmental monitoring of these structures and the associated mobile fauna (such as invertebrates, fish, marine mammals and seabirds) gives the relevant information on the ecosystem functioning of MRE devices. Earlier studies have shown impacts and changes of the local species distribution, abundance, biodiversity and connectivity $[5,6]$. Comparable studies on offshore wind turbines give a wider picture on the development of arrays and park effects, and their possible function as marine protected areas [7]. Likewise, earlier studies on the generation of electromagnetic fields (EMF) from subsea power cables have shown effects on the orientation, navigation and predation behaviour of electrosensitive species, such as elasmobranches [8]. However, it is still not clear whether generated EMF will induce attraction or avoidance behaviour in certain sensitive species [9]. As mitigation measures for MRE devices, buried sea-cables, and the reduction of the EMFs by better isolated transmission systems have been discussed [10].

The role of underwater noise as potential stressor has been of importance since earlier studies have shown a change in the behaviour of some marine organisms. Navigation, communication, predation behaviour of harbour porpoise was affected negatively by noise emissions [11,12]. Especially, pile-driving during construction of MRE devices will emit the loudest and most disruptive noises and have been shown to cause large-scale avoidance and displacement of marine mammals and fish [13-15]. For other offshore industries, mitigation measures have been developed [16] and for MRE installations, alternative mooring systems, such as gravitybased foundations have been recommended [17]. Noise from the operation of MRE devices has been measured and it has been shown to occur at lower frequencies compared to e.g. shipping noise $[18,19]$. This preliminary conclusion that single devices may not pose a significant threat to the marine communities need to be complemented by studies of the reaction of marine organisms to the underwater sounds cape of MRE arrays and new developed devices. Underwater collisions of marine organisms with tidal energy and ocean current devices pose the, up to this date, largest risk and concern for marine wildlife and a challenge for consenting and permitting procedures. MRE devices are rather big and operate with low rotational speeds [20]. Aside with the technological development of ocean and tidal energy devices, the assessment of collision risks is going on, but is still at its infancy. There is a big challenge related to the monitoring of environmental interactions, since installations are and will be deployed in high-energy sites with current velocities usually above $1 \mathrm{~m} / \mathrm{s}$. Up to date, smallscale and single devices that have been deployed and observed for shorter periods of time under field conditions using visual or acoustic observation techniques $[21,22]$.

So far, field studies neither observed any collision or strikes of turbine-animal interactions, nor injuries or mortality related to animal-turbine strikes. Field studies of animal-turbine interactions could however show the effect of tidal turbines on behavior of fish, seals and seabirds, in terms of avoidance, evasion, entering, passing or even remaining in the wake [23]. A possible attraction by fish to the turbines, and their function as fish aggregation devices has been suggested to have further implications for the local ecology, since these areas may even lure larger predatory species, such as larger fish, marine mammals and diving seabirds. MRE-park and wildlife interactions need to be understood before the expansion from a single-device to multiple-device arrays. Therefore, new observational methods, and data gathering on and continuous monitoring of animal-turbine interactions are essential for speciesspecific collision risk-assessments since these risks will increase with the deployment of arrays. In order to prevent severe effects on marine species and populations, observed device-effects need be scaled up prior to their deployment [24-27].

\section{Conclusion}

Still, MRE installations are not fully integrated into marine spatial planning or ecosystem-based management, and adequate decisions and actions of MRE development is a challenge for national decision- and policy-makers. While MRE technologies reduce carbon emissions and contribute to the overall renewable energy mix targets established by the EU Renewable Energy Directive, their impact on the marine environment and existing ES needs to be further assessed [28]. The adequate management and planning of maritime space is considered a challenge for governments and policy-makers that need to enforce European Directives as the Marine Spatial Planning (MSP) and the Marine Strategy Framework Directive (MSFD). Intertwined in these legislations are also the Common Fisheries Police and the EU Biodiversity Strategy to 2020 that consider monitoring and assessing ecosystems and their services as focus areas. Forecasting models of array-effects increase the understanding of both risky and sustainable interactions between energy production and the marine environment [29]. Appropriate, targeted and effective mitigation measures are under discussion, and some have already been tested [30]. The development of MRE respecting nature in terms of environmental designs is the key-element that includes the integration of technical, environmental and social aspects from the beginning in the planning, building and operational phases of MRE installations for a sustainable future.

\section{Acknowledgement}

This work was carried out as part of the Swedish Energy Agency project P42233-1 "Exploring and mitigating the environmental risk of hydrokinetic turbines". This support is gratefully acknowledged.

\section{References}

1. Papathanasopoulou, Beaumont EN, Hooper T, Nunes J, Queirós AM (2015) Energy systems and their impacts on marine ecosystem services. Renewable and Sustainable Energy Reviews 52: 917-926.

2. Long, RD, Charles A, Stephenson R (2015) Key principles of marine ecosystem-based management. Marine Policy 57: 53-60.

3. Hammar L, Andersson S, Eggertsen L, Haglund J, Gullstrom MJ, et al. (2013) Hydrokinetic turbine effects on fish swimming behaviour. 8(12).

4. www.ocean-energy-systems.org 
5. Copping AS, Hanna N, Whiting L, Zydlewski J, Staines G, et al. (2016) Annex IV 2016 State of the Science Report: Environmental Effects of Marine Renewable Energy Development around the World. Ocean Energy Systems.

6. Hammar L, Gullstrom M, Dahlgren T, Asplund ME, Braga Goncalves I, et al. (2017) Introducing ocean energy industries to a busy marine environment. Renewable \& Sustainable Energy Reviews 74: 178-185.

7. Langhamer O, Holand H, Rosenqvist G (2016) Effects of an offshore Wind Farm (OWF) on the Common Shore Crab Carcinus maenas: Tagging Pilot Experiments in the Lillgrund Offshore Wind Farm (Sweden). PLoS ONE 11(10): e0165096.

8. Langhamer O, Wilhelmsson D, Engstrom J (2009) Artificial reef effect and fouling impacts on offshore wave power foundations and buoys-a pilot study. Estuarine Coastal and Shelf Science 82(3): 426-432.

9. Langhamer O, Dahlgren TG, Rosenqvist G (2018) Effect of an offshore wind farm on the viviparous eelpout: Biometrics, brood development and population studies in Lillgrund, Sweden. Ecological Indicators 84: $1-6$

10. Normandeau, Exponent, Tricas T (2011) Effects of EMFs from Undersea Power Cables on Elasmobranchs and Other Marine Species. U.S. Dept. of the Interior, Bureau of Ocean Energy Management, Regulation, and Enforcement, Pacific OCS Region, Camarillo, CA. OCS Study BOEMRE 2011-09.

11. Gill AB, Taylor H (2001) The potential effects of electromagnetic fields generated by cabling between offshore wind turbines upon elasmobranch fishes. Countryside for Wale Report.

12. Gill AB, Huang Y, Gloyne Philips J, Metcalfe J, Quayle (2009) COWRIE 2.0 Electromagnetic Fields (EMF) Phase 2: EMF-sensitive fish response to EM emissions from sub-sea electricity cables of the type used by the offshore renewable energy industry. Commissioned by COWRIE Ltd (project reference COWRIE-EMF-1-06).

13. Kastelein RA, Gransier R, Marijt T, Hoek T (2015) Hearing frequency thresholds of harbor porpoises (Phocoena phocoena) temporarily affected by played back offshore pile driving sounds. Journal of the Acoustical Society of America 137: 556-564.

14. Kastelein RA, Van Heerden D, Gransier R, Hoek L (2013) Behaviora responses of a harbor porpoise (Phocoena phocoena) to playbacks of broadband pile driving sounds. Marine Environmental Research 92: 206-214.

15. Hastie G (2013) Tracking Marine Mammals Around Marine Renewable Energy Devices Using Active Sonar.

16. Madsen PT, Wahlberg MJ, Tougaard K, Lucke, Tyack P (2006) Wind turbine underwater noise and marine mammals: implications of current knowledge and data needs. Marine Ecology Progress Series 309: 279295.
17. Tougaard J, Henriksen OD, Miller LA (2009) Underwater noise from three types of offshore wind turbines: Estimation of impact zones for harbor porpoises and harbor seals. Journal of the Acoustical Society of America 125(6): 3766-3773.

18. Debusschere E, De Coensel B, Bajek A, Botteldooren D, Hostens K, et al. (2014) In Situ mortality experiments with juvenile sea bass (dicentrarchus labrax) in relation to impulsive sound levels caused by pile driving of windmill foundations. PLoS One 9(10): e109280.

19. Hammar L, Wikstrom A, Molander S (2014) Assessing ecological risks of offshore wind power on Kattegat cod. Renewable Energy 66: 414-424

20. https://www.nrel.gov/docs/fy16osti/66688.pdf

21. Lossent J, Lejart M, Folegot T, Clorennec D, Di Iorio LD et al. (2018) Underwater operational noise level emitted by a tidal current turbine and its potential impact on marine fauna. Marine Pollution Bulletin 131: 323-334.

22. https://tethys.pnnl.gov/sites/default/files/publications/ABP MER_2010.pdf

23. Viehman HA, Zydlewski GB, McCleave JD, Staines GJ (2015) Using hydroacoustics to understand fish presence and vertical distribution in a tidally dynamic region targeted for energy extraction. Estuaries and Coasts 38(1): 215-226.

24. Langhamer O, Francisco F, Bender A, Forslund J, Hammar L, et al. (2018) Pilot observations of fish behaviour around an operating hydrokinetic test turbine. Environmental Interatctions of Marine Renewable Energy Technology.

25. Viehman HA, Zydlewski GB (2015) Fish interactions with a commercialscale tidal energy device in the natural environment. Estuaries and Coasts 38(1): 241-252.

26. Hammar L, Eggertsen L, Andersson S, Ehnberg J, Arvidsson R et al. (2015) A probabilistic model for hydrokinetic turbine collision risks: exploring impacts on fish. PLoS One 10(3): e0117756.

27. Lindeboom HJ, Kouwenhoven HJ, Bergman JN, Bouma S, Brasseur S et al. (2011) Short-term ecological effects of an offshore wind farm in the Dutch coastal zone; a compilation. Environmental Research Letters 6(3): 1-14.

28. Langhamer 0 (2016) The location of offshore wave power devices structures epifaunal assemblages. International Journal of Marine Energy 16: 174-180.

29. UNEP (2006) Marine and coastal ecosystems and human wellbeing: a synthesis report based on the findings of Millennium ecosystem assessment.

30. MEA (2005) Millennium Ecosystem Assessment. Ecosystems and Human Well-being: Synthesis.
Creative Commons Attribution 4.0 International License

For possible submissions Click Here

\section{Submit Article}

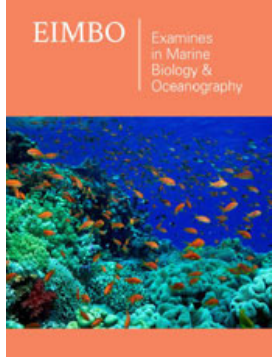

Examines in Marine Biology \& Oceanography

\section{Benefits of Publishing with us}

- High-level peer review and editorial services

- Freely accessible online immediately upon publication

- Authors retain the copyright to their work

- Licensing it under a Creative Commons license

- Visibility through different online platforms 